\title{
Serving up the self: Role identity and burnout in client service environments
}

\begin{tabular}{|c|c|}
\hline \multicolumn{2}{|l|}{$\begin{array}{l}\text { Authors: } \\
\text { Carly Steyn } 1,3 \\
\text { J.J. de Klerk }\end{array}$} \\
\hline \multicolumn{2}{|c|}{$\begin{array}{l}\text { Affiliations: } \\
{ }^{1} \text { School of Business and } \\
\text { Finance, University of the } \\
\text { Western Cape, Cape Town, } \\
\text { South Africa }\end{array}$} \\
\hline \multicolumn{2}{|c|}{$\begin{array}{l}{ }^{2} \text { University of Stellenbosch } \\
\text { Business School, Stellenbosch } \\
\text { University, South Africa }\end{array}$} \\
\hline \multicolumn{2}{|c|}{$\begin{array}{l}{ }^{3} \text { Department of Human } \\
\text { Resource Management, } \\
\text { University of Pretoria, } \\
\text { Pretoria, South Africa }\end{array}$} \\
\hline \multicolumn{2}{|c|}{$\begin{array}{l}\text { Correspondence to: } \\
\text { Carly Steyn }\end{array}$} \\
\hline \multicolumn{2}{|c|}{$\begin{array}{l}\text { Email: } \\
\text { carly.steyn@gmail.com }\end{array}$} \\
\hline \multicolumn{2}{|c|}{$\begin{array}{l}\text { Postal address: } \\
\text { Private Bag X17, Bellville } \\
7535 \text {, South Africa }\end{array}$} \\
\hline \multicolumn{2}{|c|}{$\begin{array}{l}\text { Dates: } \\
\text { Received: } 23 \text { Apr. } 2015 \\
\text { Accepted: } 18 \text { June } 2015 \\
\text { Published: } 18 \text { Dec. } 2015\end{array}$} \\
\hline \multicolumn{2}{|c|}{$\begin{array}{l}\text { How to cite this article: } \\
\text { Steyn, C., \& De Klerk, J.J. } \\
\text { (2015). Serving up the self: } \\
\text { Role identity and burnout in } \\
\text { client service environments. } \\
\text { SA Journal of Industrial } \\
\text { Psychology/SA Tydskrif vir } \\
\text { Bedryfsielkunde, 41(1), Art. } \\
\text { \#1279, } 12 \text { pages. http:// } \\
\text { dx.doi.org/10.4102/sajip. } \\
\text { v41i1.1279 }\end{array}$} \\
\hline \multicolumn{2}{|c|}{$\begin{array}{l}\text { Copyright: } \\
\text { (C) 2015. The Authors. } \\
\text { Licensee: AOSIS } \\
\text { OpenJournals. This work is } \\
\text { licensed under the Creative } \\
\text { Commons Attribution } \\
\text { License. }\end{array}$} \\
\hline \multicolumn{2}{|l|}{ Read online: } \\
\hline 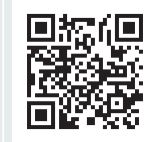 & $\begin{array}{l}\text { Scan this QR } \\
\text { code with your } \\
\text { smart phone or } \\
\text { mobile device } \\
\text { to read online. }\end{array}$ \\
\hline
\end{tabular}

Orientation: Whilst the limited investigations into the relationship between identity and burnout have made an important contribution to our understanding of the development of burnout, further research is required to gain a deeper understanding of how the processes associated with the construction and enactment of a specific identity could contribute to burnout amongst client service employees.

Research purpose: The purpose of this research was to explore whether levels of burnout amongst client service employees are associated with the manner in which they define and enact the client service role identity.

Motivation for the study: The negative effects of burnout amongst client service employees can be particularly devastating for client service organisations. A deeper understanding of the causes of burnout amongst client service employees is therefore essential if we wish to reduce the significant costs associated with burnout in this environment.

Research approach, design and method: The research strategy comprised a qualitative design consisting of semi-structured interviews.

Main findings: The results of the study indicate that the role identities of higher burnout client service employees differ from the role identities of lower burnout client service employees. Lower burnout employees view the client relationship as a partnership and experience a high level of self-verification when dealing with their clients. Higher burnout employees, on the other hand, describe themselves as subordinate to the client and exhibit strong feelings of defeat and failure when interacting with their clients.

Practical implications/managerial implications: The study shows that if client service organisations wish to reduce the detrimental effects of burnout in the workplace, they need to pay careful attention to the way in which their client service employees perceive themselves in relation to the client. Since client service employees construct role identities in response to the dominant discourse of the organisation, client service organisations should exercise caution in how they define and refer to the client-employee interaction through this discourse.

Contribution/value-add: The article makes a number of practical recommendations, which, if implemented by client service organisations, should result in lower levels of burnout, increased productivity and improved client relations. One such recommendation requires client service organisations to reframe their client discourses in such a way that client service employees are referred to as knowledge experts that are valued by their organisations.

\section{Introduction}

The sometimes excessive focus on customer orientation in the client service industry can not only have negative effects on client service, but also compromise the health of customer service employees through the development of burnout.

Job-related burnout, which has aptly been described as the 'biggest occupational hazard of the twenty first century' (Leiter \& Maslach, 2005, p. 3), can have devastating consequences at both the individual and organisational levels. At the individual level, the prolonged experience of burnout has been linked to the development of depression (Hakenen \& Schaufeli, 2012; Shani \& Pizam, 2009), anxiety (Richardsen, Burke \& Leiter, 1992) and diminished levels of self-esteem (Rosse, Boss, Johnson \& Crown, 1991). At the organisational level, employee burnout leads to increased turnover intention (Choi, Cheong \& Feinberg, 2012; Surana \& Singh, 2012), absenteeism (Petersen et al., 2011), reduced organisational commitment (Surana \& Singh, 2012), reduced job satisfaction (Tsigilis, Koustelios \& Togia, 2004) and a decrease in productivity and job performance (Leung, Chan \& Dongyu, 2011). 
A number of studies have examined the potential negative effects of burnout in customer or client service environments (Lings, Durden, Lee \& Cadogan, 2014; Low, Cravens, Grant \& Moncrief, 2001; Witt, Andrews \& Carlson, 2004). Given that client service employees play a critical role in service organisations and contribute significantly to profitability by facilitating customer engagement, satisfaction and retention (Alexandrov, Babakus \& Yavas, 2007), the negative effects of burnout amongst client service employees can be particularly devastating to the organisations for which they work. Burnout amongst client service employees has been shown to significantly reduce the quality of interpersonal work-related relationships (Singh, Goolsby \& Rhoads, 1994) resulting in compromised service levels and reduced customer satisfaction (Yagil, 2006).

Situational variables, such as job and organisational characteristics, are probably the most frequently examined antecedents to burnout in the organisational context (Crawford, LePine \& Rich, 2010; Demerouti, Bakker, Nachreiner \& Schaufeli, 2001; Low et al., 2001; Maslach, Jackson \& Leiter, 1996; Singh et al., 1994). Other antecedents include personality and dispositional factors (Swider \& Zimmerman, 2010; Witt et al., 2004) and the nature of interpersonal relationships (Bakker, Schaufeli, Sixma, Bosveld \& Van Dierendonck, 2000).

Notwithstanding some notable exceptions (e.g. Buunk, Peiro, Rodriguez \& Bravo, 2007; Edwards \& Dirette, 2010; Geng, Li \& Zhou, 2011; Kang, Twigg \& Hertzman, 2010; Lammers, Atouba \& Carlson, 2013; Vanheule, Lievrouw \& Verhaeghe, 2003; Vanheule \& Verhaeghe, 2004), surprisingly little empirical research has been conducted into the role of identity-related variables in the development of burnout, even though identity-related variables may explain more variance in burnout scores than the often-examined job and organisational variables (Buunk et al., 2007). Previous research focusing on the relationship between identityrelated variables and burnout has generally been descriptive in nature, at the expense of a deeper understanding as to exactly how these variables can contribute to burnout. As far as could be established, no work has been done to investigate how the processes of identity construction and enactment could contribute to the development of burnout. This state stands to be corrected through the present research.

\section{Research purpose and objectives}

Whilst the limited investigations into the relationship between identity and burnout have made an undeniably important contribution to our understanding of the development of burnout, further research is required to gain a deeper understanding of how the processes associated with the construction and enactment of a specific identity could contribute to burnout.

Although it has received limited attention in the organisational behaviour literature, the 'role identity' construct could contribute to our understanding of the manner in which identity construction and the enactment processes are related to burnout.

It is our contention that the nature of the client service role identity carries implications for behaviours and attitudes that could either facilitate or inhibit the development of burnout. Since the client service employees' company is largely dependent on the client for business, clients are able to exert considerable influence over client service employees through formal and informal evaluations (Gettman \& Gelfand, 2007). This results in an imbalance of interpersonal power between the employee and the client (Grandey, Dickter \& Sin, 2004), rendering client service employees susceptible to abuse, harassment and other aggressive behaviours from clients (Gettman \& Gelfand, 2007). Consequently, client service employees may construct role identities that place them in a subordinate or subservient position relative to the client.

This position of subordination and subservience may place undue demands on the individual, ultimately resulting in feelings of emotional exhaustion and reduced personal accomplishment. Furthermore, if the role-related expectations contained in the client service role identity are impossible to meet, the client service employee may struggle to achieve selfverification. In keeping with the sentiments expressed by the existentialists (Cherniss, 1993), failure to meet organisational and personal expectations could result in reduced feelings of self-efficacy and personal accomplishment, which could ultimately lead to burnout.

The primary objective of this research is therefore to explore whether levels of burnout amongst client service employees are associated with the manner in which they define and enact the client service role identity. Our research is guided by the following research question: To what extent is burnout amongst client service employees associated with the manner in which they define and enact the client service role identity?

Using a grounded theory approach (Kahn, 2014; Kenny \& Fourie, 2014) we explore how the role identities of client service employees carry implications for role-related attitudes and behaviours that could either facilitate or inhibit the development of burnout.

\section{Literature review}

\section{Burnout}

Maslach et al. (1996) conceptualise burnout as comprising three dimensions, namely emotional exhaustion, depersonalisation and feelings of reduced personal accomplishment. Emotional exhaustion manifests as both physical and psychological stress and is characterised by a loss of energy and feeling worn out, helpless and hopeless. Depersonalisation refers to the interpersonal aspect of burnout and is characterised by attempts to distance oneself psychologically from service recipients. It is accompanied by a detached, emotionally callous attitude towards service recipients. Reduced personal accomplishment comprises an aspect of self-evaluation and is characterised by negative 
evaluations of the self and feelings associated with failure (Maslach et al., 1996).

Situational or organisational antecedents are the most frequently cited antecedents to burnout, prompting scholars to conclude that burnout develops in response to excessive job demands and a lack of available resources to cope with these demands (e.g. Crawford et al., 2010; Demerouti et al., 2001). Job demands are those physical, social and organisational aspects of the job that require prolonged physical and mental effort (Demerouti et al., 2001) and can be classified as either quantitative or qualitative. Quantitative job demands occur when there is too much work for the available time, resulting in role overload, whilst qualitative job demands include aspects related to role conflict and role ambiguity (Maslach et al., 1996). Job resources refer to the physical, psychological, social and organisational aspects of the job that may assist an individual in achieving work goals, reduce job demands and stimulate personal growth and development (Demerouti et al., 2001). They include aspects related to job control and autonomy (Fernet, Guay \& Senécal, 2004), feedback and participation in decision-making (Xanthopoulou et al., 2007), social support (Albar Marín \& García-Ramírez, 2005), supportive management, reward mechanisms, training and appropriate technology (Rod \& Ashill, 2009).

Job demands (mental, emotional or physical) exhaust the employee's physical and emotional resources, resulting in excessive strain, exhaustion and health problems (Demerouti et al., 2001). The availability of job resources, on the other hand, plays a motivational role in that it enhances individual growth and development and facilitates the achievement of work goals (Bakker \& Demerouti, 2007).

The development of burnout has also been attributed to the nature of interpersonal relationships at work, prompting Cordes and Dougherty (1993) to conclude that the clientemployee relationship remains the most critical variable in the study of burnout. In the context of social exchange and equity theory, a perceived lack of reciprocity in an employee's interactions with their service recipients or clients could initiate the development of burnout. Relationships are judged as equitable if investments ploughed into the relationship are perceived as equal to the outcomes or benefits associated with the relationship (Bakker et al., 2000). Client service employees are likely to perceive their relationships with their clients as equitable if the effort they put into the relationship is reciprocated through signs of appreciation or gratitude from the client.

The antecedents of burnout have also been examined from an existential perspective (Pines, 2002). According to this perspective, burnout develops as a result of thwarted attempts to establish personal meaning through work. It is premised on the notion that the root cause of burnout lies in people's need to believe that their life is meaningful, that the things they do, and consequently they themselves, are important and significant' (Pines, 2002, p. 123). In the work context, the development of burnout can be linked to a sense of failure to accomplish goals and expectations through work (Pines, 2002). This aspect has specific relevance to the development of burnout amongst client service employees.

\section{Stress and burnout in client service organisations}

Client service employees can be defined as individuals in service positions who fulfil a boundary-spanning role between the service organisation and customers on a regular basis through the use of telephonic, face-to-face or electronically facilitated communication. Because of this boundary-spanning role, client service employees are exposed to a number of stressors, which could facilitate the development of burnout.

The manner in which organisations symbolically and abstractly refer to their clients through the client discourse of the organisation carries implications for the way in which client service employees perceive their relationships with their clients (Anderson-Gough, Grey \& Robson, 2000). Organisations with a strong service ethic, for instance, may define the client in such a way as to suggest to employees that they subordinate their own needs in order to adequately meet the needs and desires of the client. Furthermore, the performance of client service employees is generally measured through the satisfaction of both the clients that they serve and the organisations for which they work. Chung and Schneider $(2002$, p. 71) put this succinctly when they state that 'in manufacturing firms there is only one distinct authority or boss, whereas in service firms there is another master to serve - the customer'. As a result, client service employees often find themselves in precarious positions professionally, when they have to reconcile the needs of the organisations for which they work with the conflicting needs of the client. Client service employees can therefore find themselves in compromising and emotionally exhausting positions when they believe that they are unable to meet the demands of their clients (Cordes \& Dougherty, 1993). This feeling of incompetence is strengthened when employees feel that they are not sufficiently empowered due to organisational policies or when they lack the necessary skills and aptitude to deal adequately with client requests (Varca, 2009).

The role that such perceived failure and helplessness play in the development of burnout is evidenced in the research of Vanheule et al. (2003) and Vanheule and Verhaeghe (2004). Their research shows that high burnout service employees display a strong sense of personal obligation towards their clients and often manifest feelings of powerlessness in their interactions with their clients. These individuals tend to identify closely with the problems of their clients and often feel threatened in their dealings with them. Low burnout individuals, on the other hand, manage to maintain a subjective distance from their clients, hold flexible expectations with regard to recipient outcomes and attribute failure to the client context rather than to their own inadequacies. Similarly, Buunk et al. (2007) show how burnout is related to being placed in an unwanted or 
subordinate position, resulting in feelings of powerlessness, inferiority, shame and guilt.

\section{Role identity}

Role identity can be described as the meanings that individuals attach to themselves within particular situations (Stryker, 1980). Hogg, Terry and White (1995, p. 256) describe role identities as the 'self-conceptions, self-referent cognitions or self-definitions that people apply to themselves as a consequence of the structural role positions they occupy'. As such, role identities include an organised collection of behavioural expectations and demands (identity standards) associated with the various roles people assume during social interaction (Neale \& Griffin, 2006). As self-descriptions, role identities act as a frame of reference that individuals use to interpret the social situations in which they find themselves and to then evaluate the extent to which they are living up to these identity expectations (Hogg et al., 1995).

Role identities are highly relational in that the identity assumed by a particular individual in a specific position is always related to an alternative or counter identity (Burke, 1991). In the client service setting, for instance, the client service employee forms an identity in relation to that of the client.

In the organisational setting, role identities and their associated behavioural expectations are communicated to the employee through the dominant discourse of the organisation (Alvesson \& Willmott, 2004). In the client service setting, relevant discourse would comprise any company texts (written and verbal) that contain role-related expectations of what constitutes a good client service employee. Job descriptions, training manuals, performance agreements, marketing brochures and company newsletters would all contain assumptions (often implicit) about what it means to be a client service employee in that specific organisation (Anderson-Gough et al., 2000). In order to function effectively as members of their organisations and avoid sanctions, individual employees internalise these discourses to varying degrees. From these internalisations they construct role identities based on the organisational expectations implied by this discourse (Blenkinsopp \& Stalker, 2004).

As indicated in Figure 1, when an individual engages in role-related behaviour a feedback loop is established through which the individual compares their role-related expectations (identity standards) with the result of their behaviour (output). When an individual's appraisal of their role-related behaviours match the meanings contained in the identity standard, identity is verified and people continue to act as they have been. If, however, there is a mismatch between the identity standard and the individual's appraisal of their behaviour, the person will act to counteract this imbalance (Burke, 2004). For example, all client service employees will have certain self-expectations in terms of how they believe they should enact the client

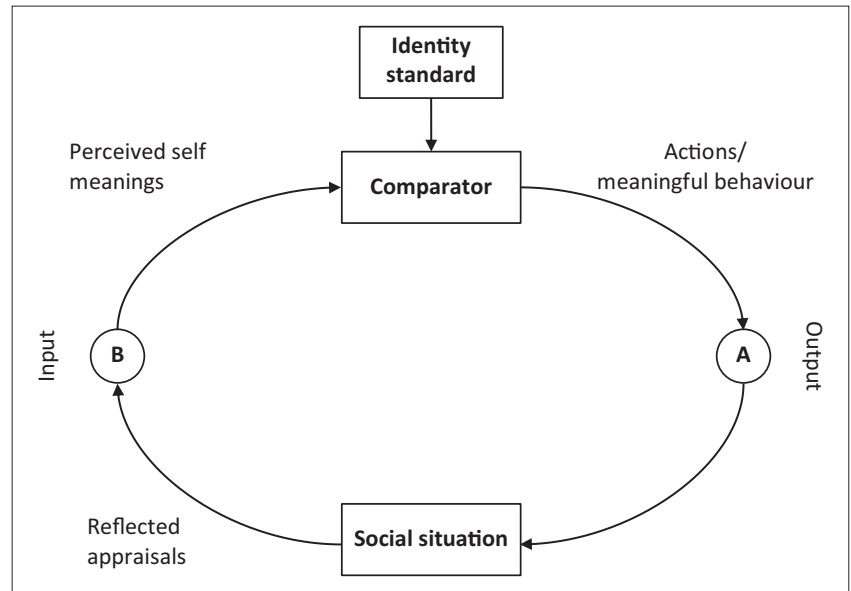

Source: Burke, P.J. (1991). Identity processes and social stress. American Sociological Review, 56, 836-849. http://dx.doi.org/10.2307/2096259

FIGURE 1: Burke's cybernetic control model.

service role. When engaging in role-related behaviour, they will appraise their behaviours based on how they perceive the outcomes of these behaviours. If their appraisals of their behaviours are in accordance with the expectations contained in the identity standard, they will experience self-verification, accompanied by increased self-esteem and feelings of personal mastery (Cast \& Burke, 2002). If a discrepancy between the outcomes of their behaviours and their expectations exists, negative emotional arousal in the form of depression, distress, anger and hostility can occur (Stets \& Burke, 2003).

\section{Research design Research approach and strategy}

Based on the grounded theory approach (Kahn, 2014; Kenny \& Fourie, 2014), the research strategy comprised a qualitative design consisting of semi-structured interviews. Respondents for the semi-structured interviews were purposively selected following the application of the Maslach Burnout Inventory Human Services Survey (MBI-HSS) (Maslach et al., 1996) amongst a sample of 217 client service employees representing three South African client service organisations from different service sectors.

Since the aim of the research was to compare the role identities of high burnout respondents with the role identities of low burnout respondents, the responses to the MBI-HSS were stratified into employees scoring highest and those scoring lowest on burnout. Semi-structured interviews were then conducted with a purposively selected sample of both high and low burnout employees.

\section{Research method}

\section{Research setting}

All 217 potential respondents were posted a hard copy selfadministered questionnaire of the MBI-HSS. Respondents were informed that participation in the research was voluntary and confidential, but were made aware that anonymity was not possible as names were required for 
confidential follow-up interviews. Individual interviews were scheduled with the purposively selected respondents at a time and place convenient to them. All respondents chose to have the interviews at their place of work and interviews lasted approximately 45 minutes. Interviewees were put at ease at the beginning of the interview and assured of the confidentiality of their responses.

\section{Entrée and establishing researcher roles}

Formal approval to conduct the research was obtained from authorised managers at all three participating organisations. Interviewees were asked to consent to the recording of the interview for the purpose of transcription and signed an informed consent form that outlined the purpose of the research and guaranteed confidentiality.

\section{Research participants and sampling methods}

The three companies that participated in the study each represent different service sectors, thereby ensuring that a diverse range of employees exposed to a diverse range of client service environments were included in the study. All 65 research and account executives from Company $\mathrm{M}$, all 47 inbound call centre consultants from Company $\mathrm{F}$ and all 105 customer and network engineers from Company $\mathrm{T}$ were invited to participate in the research. To be considered for inclusion, individual respondents were required to engage with clients on a daily basis. The type of engagement was not specified and could include telephonic, face-to-face or electronically facilitated communication. A total of 100 responses to the MBI-HSS were returned, reflecting a response rate of $46 \%$. From Company M 23 responses were received, 20 were received from Company $\mathrm{F}$ and 57 from Company $\mathrm{T}$.

Following administration of the MBI-HSS, burnout scores per respondent were calculated and ranked from highest to lowest. The MBI-HSS provides burnout scores along a continuum ranging from high burnout to low burnout. Scores are considered high when they are situated in the upper third of the normative distribution. Average scores are situated in the middle third, whilst low scores are situated in the lower third (Maslach et al., 1996). In the present study, high burnout would be indicated by a score above 84 , whilst low burnout would be indicated by a score below 42 . Only one respondent in the present sample could be classified as displaying high burnout. Forty respondents were classified as displaying moderate levels of burnout (with scores between 42 and 85) whilst the rest were classified as displaying low burnout. Since the aim of the research was to compare the role identities of high and low burnout employees, the 16 respondents measuring the highest in total burnout and the 16 respondents scoring the lowest on total burnout were invited to participate in the interviews. In order to ensure representation of the three companies, at least two respondents from each of the three companies were included in both the higher and lower burnout group and invited for interviews. A total of eight higher burnout and nine lower burnout interview respondents eventually agreed to be interviewed. The higher burnout group included one respondent who could be regarded as experiencing high burnout, whilst the other seven displayed moderate levels of burnout, with burnout scores ranging from 60-75. All respondents in the lower burnout group reflected low levels of burnout, with burnout scores between 6 and 20 .

The mean age of respondents was 32.6 years. The higher burnout group included three female and five male subjects, whereas the lower burnout group consists of four female and five male subjects. Five of the higher burnout subjects were from the white population group, whilst the other three were mixed-race. All the subjects in the lower burnout grouping were white. The higher burnout group included two subjects from Company $\mathrm{M}$, three from Company $\mathrm{F}$ and two from Company T. The lower burnout group included three subjects from Company $\mathrm{M}$ and six from Company T. No lower burnout respondents from Company $\mathrm{F}$ were included in the interview sample. It is unlikely that this would have affected the results of the research in any meaningful or significant way, given that the specific type of client service work conducted by the respondents did not appear to meaningfully affect the construction of the client service role identity in this diverse sample.

Whilst a number of demographic and biographic variables (including marital status and organisational tenure) have been associated with the development of burnout (Kuruuzum, Anafarta \& Irmak, 2008), none of these variables displayed a significant relationship with burnout as measured by the present study. None of these variables was therefore used as a criterion for selecting the qualitative sample.

\section{Data collection and recording}

The semi-structured interviews were designed to elicit rich, reflective narratives from client service employees relating to self-definitions and expectations for role-related behaviours.

The interview schedule commenced with a general question asking the respondent to explain their specific role in the organisation. This was followed by questions relating to the client and the client relationship, employee perceptions of management expectations and role-related expectations.

The interview schedule made use of descriptive and experience or example questions (Janesick, 2004). The use of experience questions was regarded as particularly important in order to understand the level of congruence between respondents' perceptions and actual behaviours. Probing took various forms including silence, encouragement, asking for immediate clarification, retrospective clarification, immediate elaboration or retrospective elaboration (Keats, 2000, p. 64).

All semi-structured interviews were digitally recorded and accompanied by field notes before they were transcribed verbatim. 


\section{Strategies employed to ensure data quality and integrity}

As proposed by Morse, Barret, Mayan, Olson and Spiers (2002), a number of verification strategies to ensure the rigour of qualitative data were used in this study. Burnout was measured objectively through application of the MBIHSS, before conducting the interviews. Maximum likelihood factor analysis (MLFA) was conducted on the MBI-HSS data to ascertain that the factor structure produced by the sample corresponded to that identified by Maslach et al. (1996). The analysis delivered a two-factor solution and one item was removed from the instrument due to strong cross-loading.

The quantitative stratification of the sample into high burnout and low burnout client service employees contributed to the trustworthiness of the results as the interviewer had an objective measure of burnout rather than having to infer burnout levels from the interviews. The semistructured interviews, which were all conducted by the same interviewer, facilitated analytical comparison between each of the respondents and allowed the researcher to probe for clarity in cases of ambiguity.

Explanations for qualitative observations are generally confirmed by the literature and where observations are not confirmed, it is clearly stated. Methodological and analytical coherence were ensured by considering the study's research questions during both axial and selective coding. Qualitative conclusions were drawn by comparing and contrasting cases, and negative instances are clearly mentioned and accounted for. Although a number of respondents declined to participate in the qualitative interviews, every effort was made to ensure that only respondents representing the highest and lowest burnout scores were included in the sample, thereby ensuring an appropriate sample.

\section{Data analysis}

All interviews were transcribed verbatim and analysed using Atlas.ti ${ }^{\mathrm{TM}}$ scientific software. Data were analysed by comparing the role identities and associated dimensions of higher burnout employees with those of lower burnout employees. A multi-strategy approach (Layder, 1998) to data analysis and interpretation was employed, by taking into account existing theoretical ideas during analysis, but also allowing for themes to develop directly as a result of familiarity with the data (Lewins \& Silver, 2007). The coding process followed the analysis approach suggested by Grbich (2007) and Miles and Huberman (1994), commencing with open coding, followed by axial coding and then selective coding. During the open coding phase, a total of 391 codes were created in the higher burnout hermeneutic unit, whilst a total of 322 codes were initially created in the lower burnout hermeneutic unit. Once the open coding process was completed, axial coding commenced in which codes generated through open coding were reconsidered and similar codes were grouped together. A total of 30 codes were eventually created in the higher burnout hermeneutic unit and 21 codes were created in the lower burnout hermeneutic unit. Finally, selective coding was conducted in which initial categories were examined in terms of their temporal and spatial relationships and were provided with context, resulting in the following six themes:

- client service employee perceptions of the client

- self-descriptions of the client service role

- role-related behavioural expectations

- behavioural and affective implications of the role identity

- evidence of self-verification or failure of self-verification

\section{Findings}

A number of differences between the role identities of higher burnout and lower burnout employees were observed and are presented in sections corresponding to the primary themes that emerged during data analysis.

\section{Client service employee perceptions of the client}

Higher burnout respondents differ from their lower burnout counterparts in their descriptions of the client. Higher burnout respondents describe the client as powerful, controlling, authoritarian and having unreasonable expectations. Five of the eight higher burnout respondents describe their clients as abusive and included references to being 'threatened' by the client, 'taking punches' from the client and being 'undermined' and 'crushed' by the client. One respondent was made to feel like a 'piece of dirt' beneath the client's feet and another describes having clients that 'crack you down as a person'.

On the other hand, lower burnout respondents appear to exhibit more positive perceptions of the client. Although they perceive the client as demanding, they view their clients as appreciative, understanding and trusting: 'She appreciates what I do and she appreciates the effort I make and she is really lovely to deal with' (Respondent 10); 'The clients here are - I like to work with them, they are understanding and they listen' (Respondent 16).

\section{Self-descriptions of the client service role}

The second theme that emerged from the data includes reference to the manner in which client service employees define their roles in relation to the client.

Higher burnout respondents view themselves as subordinate to the client and generally display a sense of defeat when dealing with the client:

'I think it would be "underdog" for one. I think I say underdog because most of the time we end up having to do what the client says anyway.' (Respondent 1, when asked to describe what it is like being a client service employee)

'So ja, it does make you feel a little bit like you aren't adding anything and you are not worth much, and I think you kind of get used to that.' (Respondent 4) 
Lower burnout respondents, on the other hand, define themselves as superior to and more knowledgeable than the client. They feel confident in being able to satisfy the needs of the client and describe themselves as knowledgeable experts who can add value to the client's business:

'The client always thinks he is right. As soon as you get into a company that services clients, it's the first things that you learn the client is always right. Even though you know they are not.' (Respondent 16)

'The client is important, but not as important as our own people.' (Respondent 15)

'The tasks they give you might sound impossible, but if you have the mentality of it's impossible, you are not going to get very far. The challenges are that nothing is impossible; it's a mindset.' (Respondent 12)

\section{Role-related behavioural expectations}

The next theme that emerged from the data makes reference to the behavioural expectations of client service employees.

The behavioural expectation occurring most frequently amongst higher burnout respondents is a belief that the client always comes first no matter what. Included in this expectation is a sense of self-sacrifice on the part of the client service employee:

'I also have to maintain the relationship in terms of ensuring that their [the clients'] requests are met and that anything they ask for, we say "how high"?' (Respondent 1)

'I don't know how a mother feels, but if a child wants attention here and a husband wants attention there, it is a lot of dragging on you. Sometimes it gets like you are pulled here and pulled there and you need to perform to help the client. The primary person in this whole thing would be the client.' (Respondent 4)

Higher burnout respondents are also particularly aware of the service standards expected by organisational management and appear bound by these. When describing their roles, all higher burnout respondents mention that they often have to go above and beyond the call of duty to assist the client. In many cases, they are even prepared to go against company processes and procedures in order to keep the client happy: 'Even though there are processes and procedures, there comes a time when you have to jump the bridge' (Respondent 8); 'You have to make a decision. Even if it is not $100 \%$ following process - each and every call is a different scenario' (Respondent 5).

Lower burnout respondents, on the other hand, clearly endeavour to partner with the client. A number of lower burnout respondents actually use the word 'partner' or 'partnership' when describing the relationships they have with their clients, whilst other lower burnout respondents refer to the relationship as symbiotic, in that both the client and the client service employee or company derive some benefit from the relationship. Although lower burnout respondents do aim to assist the client to the best of their ability, they are able to separate themselves from the role and do not take the client's demands personally: 'We want to be a consultant role and really work with the client and become like a partner for them' (Respondent 10); 'And we work together - you know, we don't just work, they [the client] do their bit as well' (Respondent 12).

\section{Behavioural and affective implications of the role identity}

The next theme that emerged from the data makes reference to the behavioural, affective and attitudinal implications of identity expectations for client service employees.

Higher burnout respondents tend to personalise the client relationship and take personal responsibility for the client's demands. By identifying with the clients problems and empathising with them, higher burnout respondents tend to internalise the client's needs. One higher burnout respondent refers to developing 'broad' shoulders in order to bear the client's problems, whilst another mentions that the stress experienced by her client tends to 'ripple' into her:

'You kind of make a guardian angel or angel of some sort. You are there to listen to the client's problems and assist them. Most of the time it is - I mean it is a personalised business.' (Respondent 5)

'So, I think their [the client's] stress levels and the pressure they are under just ripples into us.' (Respondent 1)

The majority of higher burnout respondents also feel powerless against the client and express that they feel unable to protect themselves from the unreasonable demands made by the client. They cite numerous instances when they are unable to stand up for themselves when interacting with the client, resulting in feelings of helplessness and powerlessness: 'Most of the time from our point of view we don't have any say. I mean, I can't call the shots and say do this' (Respondent 5).

In contrast, lower burnout respondents report being able to manage the client and exert a certain degree of control and influence over the client. They are able to distance themselves from the client and appear more task-orientated when compared with higher burnout respondents. Lower burnout respondents also appear to take their roles less personally than higher burnout respondents do:

'So the clients are important, but I see them as an operational issue - operational things that must be addressed.' (Respondent 15)

'It's just one of those things - you try and deal with it to the best of your ability. I mean, you know you can't take it personally and you can't make judgments on them as a person - it's just the way they work.' (Respondent 10)

\section{Evidence of self-verification and failure of self-verification}

The next theme that emerged from the qualitative data is the level of self-verification experienced by client service employees. 
The interviews with higher burnout respondents indicated that they experience a fair amount of guilt for not helping the client and, as a consequence, feel little self-verification. They report feeling unable to help the client in the way that they would have liked - even when they have exercised all their options. Many higher burnout respondents are not happy with the quality of service they are giving the client, but feel unable to do any better. They express being 'emotionally challenged', 'emotionally drained', 'stupid' and 'in need of psychoanalysis' to cope with the stress:

\begin{abstract}
'It would be like taking a balloon, blowing it up with hot air and helium and all that. And just taking a pin and popping it and just having a clump of nothing with a hole in the end.' (Respondent 3, describing what she feels like when dealing with the client)
\end{abstract}

'Not to be nasty, but you have to have psychoanalysis later - it really gets to your head.' (Respondent 3 )

Lower burnout respondents, on the other hand, feel strong feelings of personal accomplishment when dealing with the client, suggesting that they experience self-verification. They are of the opinion that they are able to assist and impress the client and make a positive contribution to the companies for which they work. Lower burnout respondents also report receiving a great deal of appreciation from the client, contributing to the sense of self-verification:

'It's going to take time, but I can see the difference I am making.' (Respondent 12)

'I like it that you fulfil their needs and that they are happy with the work that you have done. That sense of satisfaction - it is very gratifying to feel that you've helped them, that you've improved their business somehow.' (Respondent 9)

Table 1 provides a summary of the main findings related to each of the themes that emerged from the data.

\section{Discussion \\ Outline of the results}

The purpose of this research was to explore the relationship between role identity and burnout amongst client service employees. The results from the study indicate that the self-descriptions of higher burnout respondents differ from the self-descriptions of lower burnout respondents, thereby suggesting that the role identities of higher burnout employees differ from the role identities of lower burnout client service employees. Whilst lower burnout respondents view themselves as more knowledgeable than and superior to the client, higher burnout respondents describe themselves as subordinate to the client.

Our findings also show that the role-related expectations of higher burnout employees differ from the role-related expectations of lower burnout employees. In the case of higher burnout respondents, the subordinated role identity appears to carry specific behavioural expectations that are different from the expectations contained within the role identities of lower burnout respondents. Firstly, higher burnout employees appear to internalise the organisational expectation that they assist the client no matter what. This is evidenced by the fact that higher burnout employees report they will often go above and beyond the call of duty to assist the client. In many instances, higher burnout employees will break company policy and procedure in order to address the client's demands. Whilst lower burnout employees also aim to provide excellent client service, they are able to distance themselves from the client service role and do not display evidence of breaking with company policy or procedure. According to Chung and Schneider (2002), client service employees suffer considerable stress because they are often expected to satisfy both the client and their employers. This results in considerable role conflict, characterised by incompatibility between the various expectations associated with a single role, as the needs of the client may clash with company policy and procedure. This role conflict was evident amongst the higher burnout employees that participated in the interviews. Whilst they are in most instances prepared to break company policy in order to assist the client, they are also very aware that they could be punished by the employing organisation for doing so. Lower burnout respondents do not appear to display such role conflict. They are able to distance themselves from the role and report unreasonable clients to management or co-workers.

Because lower burnout respondents describe themselves as superior to and more knowledgeable than the client,

TABLE 1: Main themes emerging from the data.

\begin{tabular}{|c|c|c|}
\hline Themes emerging from the analysis & Higher burnout respondents & Lower burnout respondents \\
\hline Client service employee perceptions of the client & $\begin{array}{l}\text { Perceive clients as powerful, controlling, authoritarian and } \\
\text { having unreasonable expectations }\end{array}$ & Perceive clients as appreciative, understanding and trusting \\
\hline Self-descriptions of the client service role & $\begin{array}{l}\text { Regard themselves as subordinate to the client } \\
\text { Experience a sense of defeat when dealing with the client }\end{array}$ & $\begin{array}{l}\text { Regard themselves as superior to and more knowledgeable } \\
\text { than the client }\end{array}$ \\
\hline Role-related behavioural expectations & $\begin{array}{l}\text { Believe the client always comes first } \\
\text { Expect to go above and beyond the call of duty to assist } \\
\text { the client }\end{array}$ & Endeavour to partner with the client \\
\hline $\begin{array}{l}\text { Behavioural and affective implications of the role } \\
\text { identity }\end{array}$ & $\begin{array}{l}\text { Personalise the client relationship } \\
\text { Identify strongly with the client's problem } \\
\text { Internalise the client's needs } \\
\text { Feel unable to protect themselves against unreasonable } \\
\text { client demands } \\
\text { Experience feelings of powerlessness }\end{array}$ & $\begin{array}{l}\text { Exert a degree of control and influence over the client } \\
\text { Able to distance themselves from the client } \\
\text { Task-orientated }\end{array}$ \\
\hline Evidence or failure of self-verification & $\begin{array}{l}\text { Experience guilt when unable to assist the client } \\
\text { Experience feelings of failure and defeat }\end{array}$ & Experience strong feelings of personal accomplishment \\
\hline
\end{tabular}


they expect cooperation and respect from the client. This expectation seems to have facilitated the development of a partnership with the client. By referring to the client service relationship as a partnership, lower burnout respondents create a culture of reciprocity between themselves and the client. This sense of reciprocity appears to inhibit the development of burnout amongst these respondents in that it implies that the client carry some responsibility for the outcome of the service relationship.

From the research results it appears that the role-related behaviours and attitudes of higher burnout employees differ from the role-related behaviours and attitudes of lower burnout employees. Lower burnout employees are far more task and solution orientated, whilst higher burnout employees are focused on establishing personal relationships with the client and tend to take sole or personal responsibility for the client. Lower burnout employees are able to distance themselves from the client service role and are able to manage and exert influence over the client, whilst higher burnout employees tend to empathise and identify with the clients' problems - possibly resulting in role overload and emotional exhaustion.

This finding that higher burnout client service employees tend to identify with and personalise the client relationship runs counter to one of the central consequences of burnout: depersonalisation. This finding is, however, congruent with the results of a study conducted by Vanheule et al. (2003) that showed that high burnout individuals display a strong sense of personal obligation towards their clients and often identify closely with the problems of their clients. Low burnout individuals, on the other hand, manage to maintain a subjective distance from the client, hold flexible expectations with regard to client outcomes and attribute failure to the client context rather than their own inadequacies (Vanheule et al., 2003).

The reason as to why higher burnout client service employees included in the present research do not depersonalise the client relationship could be explained through reference to their role-related expectations. As already indicated, the role identities of higher burnout employees entail a perceived obligation that they help the client no matter what. Most higher burnout respondents included in the qualitative phase of this research report that they experience receiving little support and resources from their companies, thereby confirming previous research that a lack of social support and resources can contribute to the development of burnout (Bakker \& Demerouti, 2007; Maslach et al., 1996). It is arguably possible that higher burnout employees are not necessarily resource deficient, but only perceive a lower level of resources, in line with a resource loss spiral perspective from the conservation of resources theory (Bakker, Hakanen, Demerouti \& Xanthopoulou, 2007; Brotheridge \& Lee, 2002). By virtue of their subordinate role identities and the fact that they describe their clients as controlling and dictatorial, higher burnout employees also perceive a lack of autonomy in and control over the client service situation. Consequently, these individuals experience a sense of powerlessness, helplessness and defeat. According to Burke's (1991) identity control model, individuals are likely to adjust their rolerelated behaviours when they perceive that the situational outcomes do not match the expectations contained in the identity standard. It could therefore be argued that higher burnout employees compensate for their lack of autonomy, control and resources by engaging with the client on a personal level. Since they are unable to assist the client appropriately through other means, empathising and identifying with the client may be the only means through which higher burnout respondents feel able to assist the client and live up to their role-related expectations. By identifying and empathising with the client, higher burnout respondents are likely to engage in role overload, resulting in the development of emotional exhaustion.

As our research has shown, the role identities of client service employees appear to carry implications for role-related behaviours and attitudes which, in turn, appear to facilitate or inhibit the development of burnout. A further way in which role identities can contribute to the development of burnout is through the process of self-verification. According to Burke (1991), individuals attempt to act in accordance with the expectations contained within the identity standard. When the individual is able to act in accordance with these standards self-verification occurs, resulting in feelings of esteem and personal mastery (Cast \& Burke, 2002). Failure to match role-related outcomes with these expectations results in failed self-verification, which could contribute to the development of burnout (Cherniss, 1980).

The results of our study show that lower burnout respondents experience a large degree of self-verification, whilst higher burnout respondents experience a sense of defeat and feel guilt for not helping the client. Higher burnout respondents also report feeling humiliated by the companies for which they work and, coupled with a sense of defeat, experience little self-verification. According to the existential perspective, the cause of burnout lies in people's desire to believe that their lives are meaningful and that the things they do are significant (Pines, 2002). Higher burnout respondents expect to help the client no matter what, but their subordinate role identities and a lack of support from the companies for which they work make the attainment of this expectation difficult. This ultimately results in a sense of defeat, unworthiness and failure.

\section{Practical implications}

The research makes a number of significant contributions. As the global service sector grows, competition amongst service firms is likely to increase. This will undoubtedly result in greater service expectations amongst the public at large and client service employees are likely to be placed under greater pressure by their service organisations. This trend is likely to result in increasing levels of burnout in the industry as a whole. It is therefore important that organisations acknowledge the part that role identity can play in the development of burnout 
and actively implement interventions aimed at creating empowered client service identities.

The manner in which client service employees perceive themselves in the client service role holds implications for the development of burnout amongst these employees. If they feel powerless and weak in relation to the client, burnout is likely to result. If, however, they feel like knowledgeable experts exercising control and autonomy within the client service role, burnout is likely to be inhibited. If client service organisations wish to reduce the detrimental effects of burnout in the workplace, they need to pay careful attention to the way their client service employees perceive themselves in relation to the client. Since client service employees appear likely to construct role identities in response to the dominant client discourse of the organisation, client service companies should exercise caution as to how they define and refer to the client-employee interaction through this discourse.

In order to inhibit the formation of subordinate and inferior role identities, service organisations must ensure that client service employees perceive their roles as being important to the success of the organisation (Grube \& Piliavin, 2000). This can be achieved by referring to client service employees as knowledgeable experts and by allowing them authority and control within the client service setting. Client service organisations should also openly acknowledge the difficulties experienced by client service employees by providing them a platform through which they are able to openly air grievances and client-related concerns.

This should facilitate the creation of a social distance between the employee and the client, which, according to Mills and Moshavi (1999), is the most appropriate way for client service professionals to maintain a degree of authority within the client service setting. Employee-client relationships characterised by psychological attachment, in which service providers attempt to create a warm and comfortable relationship with their clients, tend to elevate the authority of the client and undermine the status of the client service employee.

Through the implementation of these recommendations, client service organisations will create an empowered workforce. This should result in lower levels of burnout and, consequently, increased productivity and improved client relations.

\section{Limitations and recommendations}

As in other burnout research, the present study is also affected by causal limitations. Since both role identity and burnout are subjective experiences, it is difficult to ascertain from the research whether the role identities observed are in fact antecedents to burnout, or whether they are consequences of burnout. It has been well documented that burnout results in negative attitudes towards one's work, colleagues and clients (Leung et al., 2011). The negative attitudes of higher burnout respondents observed during the interviews may therefore be a consequence of burnout. From the qualitative research it can, however, be concluded that the negative attitudes embedded within the role identities of higher burnout respondents inform specific role-related behaviours. These behaviours appear to contribute to the development of burnout. Further confirmatory research is, however, necessary to establish causality in relation to the relationship between burnout and role identity in the client service context.

\section{Conclusion}

In this study we have demonstrated how the role identities of client service employees are associated with the development of burnout. By influencing the enactment of role-related behaviours and informing role-related attitudes and subjective perceptions, the client service role identity can either facilitate or inhibit the development of burnout. Since role identities also incorporate role-related expectations, they carry implications for the self-verification of the client service employee. As was shown through this research, the potential to self-verify is associated with lower levels of burnout.

Whilst it is acknowledged that burnout is a complex phenomenon that must be addressed on numerous fronts, service organisations and managers can greatly reduce the levels of experienced burnout by creating an organisation client discourse that positions the client service employee as an empowered partner in the service relationship. Such a discourse is likely to result in realistic expectations regarding the service relationship and lead to the formation of client service role identities that result in rewarding client service relationships.

\section{Acknowledgements Competing interests}

The authors declare that they have no financial or personal relationships that may have inappropriately influenced them in writing this article.

\section{Authors' contributions}

C.S. (University of the Western Cape) was responsible for the initial conceptualisation and empirical research, which was executed whilst she was affiliated with the University of Pretoria. J.J.d.K. (University of Stellenbosch) made contributions to the conceptualisation and the research design whilst affiliated with the University of Pretoria. Both authors contributed to writing the manuscript.

\section{References}

Albar Marín, M.J., \& García-Ramírez, M. (2005). Social support and emotional exhaustion amongst hospital nursing staff. European Journal of Psychiatry, 19, 96-106. http://dx.doi.org/10.4321/S0213-61632005000200004

Alexandrov, A., Babakus, E., \& Yavas, U. (2007). The effects of perceived management concern for frontline employees and customers on turnover intentions: The moderating role of employment status. Journal of Services Research, 9, 356-371. http://dx.doi.org/10.1177/1094670507299378

Alvesson, M., \& Willmott, H. (2004). Identity regulation as organisational control: Producing the appropriate individual. In M.J. Hatch \& M. Schultz (Eds.), Organisational identity: A reader. Oxford: Oxford University Press.

Anderson-Gough, F., Grey, C., \& Robson, K. (2000). In the name of the client: The service ethic in two professional service firms. Human Relations, 53, 1151-1174. http://dx.doi.org/10.1177/0018726700539003 
Bakker, A.B., \& Demerouti, E. (2007). The job demands-resources model: State of the art. Journal of Managerial Psychology, 22, 309-328. http://dx.doi. of the art. Journal of Managerial
org/10.1108/02683940710733115

Bakker, A.B., Hakanen, J.J., Demerouti, E., \& Xanthopoulou, D. (2007). Job resources boost work engagement, particularly when job demands are high. Journa of Educational Psychology, 99, 274-284. http://dx.doi.org/10.1037/00220663.99.2.274

Bakker, A.B., Schaufeli, W.B., Sixma, H.J., Bosveld, W., \& Van Dierendonck, D. (2000) Patient demands, lack of reciprocity and burnout: A five year longitudinal study among general practitioners. Journal of Organisational Behaviour, 21, 425-441. http://dx.doi.org/10.1002/(SICI)1099-1379(200006)21:4\%3C425::AIDJOB21\%3E3.0.CO;2-

Blenkinsopp, J., \& Stalker, B. (2004). Identity work in the transition from manage to management academic. Management Decision, 42, 418-429. http://dx.doi. org/10.1108/00251740410518903

Brotheridge, C.M., \& Lee, R.T. (2002). Testing a conservation of resources model of the dynamics of emotional labor. Journal of Occupational Health Psychology, 7 57-67. http://dx.doi.org/10.1037/1076-8998.7.1.57

Burke, P.J. (1991). Identity processes and social stress. American Sociological Review, 56, 836-849. http://dx.doi.org/10.2307/2096259

Burke, P.J. (2004). Extending identity control theory: Insights from classifie systems. Sociological Theory, 22, 574-594. http://dx.doi.org/10.1111/j.0735 2751.2004.00234.x

Buunk, A.P., Peiro, J.M., Rodriguez, I., \& Bravo, M.J. (2007). A loss of status and a sense of defeat: An evolutionary perspective on professional burnout. European Journal of defeat: An evolutionary perspective on professional burnout.
of Personality, 21, 471-485. http://dx.doi.org/10.1002/per.627

Cast, A.D., \& Burke, P.J. (2002). A theory of self-esteem. Social Forces, 80, 1041-1068. http://dx.doi.org/10.1353/sof.2002.0003

Cherniss, C. (1980). Professional burnout in human service organisations. New York: Praeger.

Cherniss, C. (1993). The role of professional self-efficacy in the etiology of burnout. In W.B. Schaufeli, C. Maslach, \& T. Marek (Eds.), Professional burnout: Recent developments in theory and research. Washington, DC: Hemisphere.

Choi, S., Cheong, K.J., \& Feinberg, R.A. (2012). Moderating effects of supervisor support, monetary rewards and career paths of the relationship between job burnout and turnover intentions in the context of call centres. Managing Service Quality, 22, 492-516. http://dx.doi.org/10.1108/09604521211281396

Chung, B.G., \& Schneider, B. (2002). Serving multiple masters: Role conflict experienced by service employees. Journal of Services Marketing, 16, 70-85. experienced by service employees. Journal of

Cordes, C.L., \& Dougherty, T.W. (1993). A review and an integration of research on job burnout. Academy of Management Review, 18, 621-656. http://dx.doi. org/10.2307/258593

Crawford, E.R., LePine, J.A., \& Rich, B.L. (2010). Linking job demands and resources to employee engagement and burnout: A theoretical extension and meta-analytic test. Journal of Applied Psychology, 95, 834-848. http://dx.doi.org/10.1037/ a0019364

Demerouti, E., Bakker, A.B., Nachreiner, F., \& Schaufeli, W.B. (2001). The job demands resources model of burnout. Journal of Applied Psychology, 86, 499-512. http:// dx.doi.org/10.1037/0021-9010.86.3.499

Edwards, H., \& Dirette, D. (2010). The relationship between professional identity and burnout among occupational therapists. Occupational Therapy in Health Care, 24 119-129. http://dx.doi.org/10.3109/07380570903329610

Fernet, C., Guay, F., \& Senécal, C. (2004). Adjusting to job demands: The role of work self-determination and control in predicting burnout. Journal of Vocational work self-determination and control in predicting burnout. Journal of Vocd
Behavior, 65, 39-56. http://dx.doi.org/10.1016/S0001-8791(03)00098-8

Geng, L., Li, S., \& Zhou, W. (2011). The relationships among emotional exhaustion, emotional intelligence and occupational identity among social workers in China. Social Behavior and Personality, 39, 309-320. http://dx.doi.org/10.2224/ sbp.2011.39.3.309

Gettman, H.J., \& Gelfand, M.J. (2007). When the customer shouldn't be king: Antecedents and consequences of sexual harassment by clients and customers. Journal of Applied Psychology, 92, 757-770. http://dx.doi.org/10.1037/0021 9010.92.3.757

Grandey, A.A., Dickter, D.N., \& Sin, H.P. (2004). The customer is not always right: Customer aggression and emotion regulation of service employees. Journal of Organisational Behaviour, 25, 397-418. http://dx.doi.org/10.1002/job.252

Grbich, C. (2007). Qualitative data analysis: An introduction. London: Sage Publications.

Grube, J.A., \& Piliavin, J.A. (2000). Role identity, organisational experiences, and volunteer performance. Personality and Social Psychology Bulletin, 26, 1108volunteer performance. Personality and Social Psych
1119. http://dx.doi.org/10.1177/01461672002611007

Hakenen, J.J., \& Schaufeli, W.B. (2012). Do burnout and work engagement predict depressive symptoms and life satisfaction? A three wave, seven year prospective study. Journal of Affective Disorders, 141, 415-424. http://dx.doi.org/10.1016/j. jad.2012.02.043

Hogg, M.A., Terry, D.J., \& White, K.M. (1995). A tale of two theories: A critical comparison of identity theory with social identity theory. Social Psychology Quarterly, 58, 255-269. http://dx.doi.org/10.2307/2787127

Janesick, V.J. (2004). "Stretching" exercises for qualitative researchers. Thousand Oaks, CA: Sage Publications.

Kahn, S.N. (2014). Qualitative research method: Grounded theory. International Journal of Business and Management, 9, 224-233. http://dx.doi.org/10.5539/ ijbm.v9n11p224
Kang, B., Twigg, N.W., \& Hertzman, J. (2010). An examination of social support and social identity factors and their relationship to certified chefs' burnout. International Journal of Hospitality Management, 29, 168-176. http://dx.doi. International Journal of Hospita
org/10.1016/j.ijhm.2009.08.004

Keats, D.M. (2000). Interviewing: A practical guide for students and professionals. Buckingham: Open University Press.

Kenny, M., \& Fourie, R. (2014). Tracing the history of Grounded Theory methodology: From formation to fragmentation. The Qualitative Report, 19, 1-9.

Kuruuzum, A., Anafarta, N., \& Irmak, S. (2008). Predictors of burnout among middle managers in the Turkish hospitality industry. Journal of Contemporary Hospitality Management, 20, 186-198. http://dx.doi.org/10.1108/09596110810852168

Lammers, J.C., Atouba, Y.L., \& Carlson, E.J. (2013). Which identities matter? A mixed method study of group, organisational and professional identities and their relationship to burnout. Management Communication Quarterly, 27, 503-536. http://dx.doi.org/10.1177/0893318913498824

Layder, D. (1998). Sociological practice: Linking theory and sociological research. London: Sage.

Leiter, M.P., \& Maslach, C. (2005). Banishing burnout: Six strategies for improving your relationship with work. San Francisco, CA: Jossey-Bass.

Leung, M., Chan, Y.S., \& Dongyu, C. (2011). Structural linear relationships between job stress, burnout, physiological stress and performance of construction project managers. Engineering, Construction and Architectural Management, 18, 312328. http://dx.doi.org/10.1108/09699981111126205

Lewins, A., \& Silver, C. (2007). Using software in qualitative research: A step by step guide. London: Sage. http://dx.doi.org/10.4135/9780857025012

Lings, I., Durden, G., Lee, N., \& Cadogan, J.W. (2014). Socio-emotional and operational demands on service employees. Journal of Business Research, 67, 2132-2138. http://dx.doi.org/10.1016/j.jbusres.2014.04.022

Low, G.S., Cravens, D.W., Grant, K., \& Moncrief, W.C. (2001). Antecedents and consequences of salesperson burnout. European Journal of Marketing, 35, 587611. http://dx.doi.org/10.1108/03090560110388123

Maslach, C., Jackson, S.E., \& Leiter, M.P. (1996). Maslach burnout inventory. Palo Alto, CA: Consulting Psychologists Press.

Miles, M.B., \& Huberman, A.M. (1994). Qualitative data analysis: An expanded sourcebook. Thousand Oaks, CA: Sage Publications.

Mills, P.K., \& Moshavi, D.S. (1999). Professional concern: Managing knowledge based service relationships. International Journal of Service Management, 10, 48-67. http://dx.doi.org/10.1108/09564239910255370

Morse, J.M., Barret, M., Mayan, M., Olson, K., \& Spiers, J. (2002). Verification strategies for establishing reliability and validity in qualitative research. International Journa of Qualitative Methods, 1(2), 1-19.

Neale, M., \& Griffin, M.A. (2006). A model of self-held work roles and role transitions. Human Performance, 19, 23-41. http://dx.doi.org/10.1207/s15327043hup 1901_2

Petersen, U., Bergström, G., Demerouti, E., Gustavsson, P., Asberg, M., \& Nygren, A. (2011). Burnout levels and self-rated health prospectively predict future longterm sickness absence: A study among female health professionals. Journa of Occupational and Environmental Medicine, 53, 788-793. http://dx.doi. org/10.1097/JOM.0b013e318222b1dc

Pines, A. (2002). Teacher burnout: A psychodynamic existential perspective. Teachers and Teaching: Theory and Practice, 8, 121-140. http://dx.doi. org/10.1080/13540600220127331

Richardsen, A.M., Burke, R.J., \& Leiter, M.P. (1992). Occupational demands, psychological burnout and anxiety among hospital personnel in Norway. Stress, Anxiety and Coping, 5, 55-68. http://dx.doi.org/10.1080/10615809208250487

Rod, M., \& Ashill, N.J. (2009). Symptoms of burnout and service recovery performance: The influence of job resourcefulness. Managing Service Quality, 19, 60-84. http:// dx.doi.org/10.1108/09604520910926818

Rosse, J.G., Boss, R.W., Johnson, A.E., \& Crown, D.F. (1991). Conceptualising the role of self-esteem in the burnout process. Group and Organisation Management, 16 428-451. http://dx.doi.org/10.1177/105960119101600406

Shani, A., \& Pizam, A. (2009). Work-related depression among hotel employees. Cornell Hospitality Quarterly, 50, 446-459. http://dx.doi. org/10.1177/1938965509344294

Singh, J., Goolsby, J.R., \& Rhoads, G.K. (1994). Behavioural and psychological consequences of boundary spanning burnout for customer service representatives. Journal of Marketing Research, 31, 558-569. http://dx.doi.org/10.2307/3151883

Stets, J.E., \& Burke, P.J. (2003). A sociological approach to self and identity. In M. Leary \& J. Tangney (Eds.). Handbook of self and identity (pp. 128-152). New York: Guilford Press.

Stryker, S. (1980). Symbolic interactionism: A social structural version. Palo Alto, CA: Benjamin Cummings.

Surana, S.J., \& Singh, A.K. (2012). The effect of job burnout on job outcomes among call centre customer service representatives in India. International Journal of Intelligent Enterprise, 1, 270-289. http://dx.doi.org/10.1504/IJIE.2012.052557

Swider, B.W., \& Zimmerman, R.D. (2010). Born to burnout: A meta-analytic path mode of personality, job burnout and work outcomes. Journal of Vocational Behavior, 76, 487-506. http://dx.doi.org/10.1016/j.jvb.2010.01.003

Tsigilis, N., Koustelios, A., \& Togia, A. (2004). Multivariate relationship and discriminant validity between job satisfaction and burnout. Journal of Managerial Psychology, 19, 666-675. http://dx.doi.org/10.1108/02683940 410559365 
Vanheule, S., Lievrouw, A., \& Verhaeghe, P. (2003). Burnout and intersubjectivity: A psychoanalytical study from a Lacanian perspective. Human Relations, 56, 321-338. http://dx.doi.org/10.1177/0018726703056003614

Vanheule, S., \& Verhaeghe, P. (2004). Powerlessness and impossibility in special education: A qualitative study on professional burnout from a Lacanian perspective. Human Relations, 57, 497-519. http://dx.doi.org/10.1177/0018726 704043897

Varca, P.E. (2009). Emotional empathy in frontline employees: Does it make sense to care about the customer? Journal of Services Marketing, 23, 51-56. http://dx.doi. org $/ 10.1108 / 08876040910933093$
Witt, L.A., Andrews, M.C., \& Carlson, D.S. (2004). When conscientiousness isn't enough: Emotional exhaustion and performance among call centre customer service representatives. Journal of Management, 30, 149-160. http://dx.doi. org/10.1016/j.jm.2003.01.007

Xanthopoulou, D., Bakker, A.B., Dollard, M.F., Demerouti, E., Schaufeli, W.B., Taris, T.W. et al. (2007). When do job demands particularly predict burnout? The moderating role of job resources. Journal of Managerial Psychology, 22, 766-786. http:// dx.doi.org/10.1108/02683940710837714

Yagil, D. (2006). The relationship of service provider power motivation, empowerment and burnout to customer satisfaction. International Journal of Service Industry Management, 17, 258-270. http://dx.doi.org/10.1108/09564230610667104 